TP Periodica Polytechnica Chemical Engineering

62(1), pp. 106-113, 2018

https://doi.org/10.3311/PPch.9780

Creative Commons Attribution (i)

RESEARCH ARTICLE

\section{Characterization of lon Exchange Membranes with Special Surface Structure}

\author{
Eliška Stránská ${ }^{1 *}$, Kristýna Weinertová ${ }^{1}$, David Neděla ${ }^{1}$, Jan Křivčík ${ }^{1}$
}

Received 21 July 2016; accepted after revision 30 December 2016

\begin{abstract}
This article focuses on the preparation of the heterogeneous ion exchange membrane with a special surface structure made with three types of knitted fabric. The special surface structure of ion exchange membranes can be useful for the intensification of mass transfer processes in electrodialysis.

Three types of structured ion exchange membranes were prepared together with a membrane with a flat surface to compare the influence of geometrical structures on the behaviour of ion exchange membrane properties. Electrochemical, mechanical and physical properties were determined. Structured membranes exhibited comparable electrochemical and physical properties to the flat ion exchange membrane. Some transport parameters were measured in an electrodialysis stack with two concentrations of solution. Two electrodialysis stacks with different sizes of active area were used for comparison.

Improving efficiency and mass flux was not confirmed. It was not demonstrated that structured IEMs were not better than IEMs with the flat surface.
\end{abstract}

\section{Keywords}

structured IEM, characterization of IEM, electrodialysis

${ }^{1}$ MemBrain s.r.o., Pod Vinicí 87, Stráž pod Ralskem, 471 27, Czech Republic

*Corresponding author, e-mail: Eliska.Stranska@membrain.cz

\section{Introduction}

The intensification of mass transfer processes in electrodialysis (ED) is one of the most important problems in membrane electrochemistry. One of the promising ways of this intensification is the creation of microscopic relief on the surface of an ion exchange membrane (IEM) [1]. The first successful application of structured membranes in reverse electrodialysis (RED) was achieved by Vermaas et al. [2]. A high power density and reduced hydraulic friction was obtained. Nowadays, profiled IEMs find extensive application in RED desalination of natural waters and processing solutions, and generation of electrical energy [2, 3]. Structured membranes are usually used in desalination of a solution in the range of concentrations from $10^{-5}$ to $10^{-1} \mathrm{~mol} \mathrm{dm}^{-3}$ [4]. Typical ED stacks use non-conductive spacers that block ion transport [5]. The stack with structured membranes creates channels for the feed water therefore the use of spacers is not necessary. The electrochemical resistance is significantly lower for a stack with structured membranes compared to the stack with spacers $[2,6,7]$.

Some advantages of structured IEMs are the large surface area of the membrane, the low cell resistance (low energy consumption) and the absence of inert spacers between the profiled membranes (low investment costs) [3,8]. The main advantages of profiled membranes are the more developed mass exchange surface and the increased mass transfer owing to the generation of electro convective vortices on the profile elements [11].

Structured membranes can be produced by many different techniques, such as calendaring (roll-pressing) thermoplastic ion exchange film between rollers with a geometrical structure at an elevated temperature $[6,9,10]$, hot pressing (hot embossing) of ion exchange film $[1,2,7,9,11]$ and casting a solution of ion exchange material followed by evaporation of the solvent $[5,12,13,14]$.

Hot pressing and calendaring can only be used for thermoplastics, but membranes are usually structured on both sides. The most typical problems are ruptures or deformation of the microstructures which occur during the release of the membrane film from the melt [16]. Moreover, electrochemical 
Table 1 Properties of knitted fabrics used for structured membranes (MD - machine direction, TD - transverse direction)

\begin{tabular}{|c|c|c|c|c|c|c|c|c|c|}
\hline Designation of IEM & Fabric & $\begin{array}{l}\text { Thickness } \\
(\mu \mathrm{m})\end{array}$ & $\begin{array}{l}\text { Warp } \\
(1 / \mathrm{cm})\end{array}$ & $\begin{array}{l}\text { Weft } \\
(1 / \mathrm{cm})\end{array}$ & $\begin{array}{l}\text { Open area } \\
(\%)\end{array}$ & $\begin{array}{l}\text { Force MD } \\
\text { (N) }\end{array}$ & $\begin{array}{l}\text { Force TD } \\
(\mathrm{N})\end{array}$ & $\begin{array}{l}\text { Strain MD } \\
(\%)\end{array}$ & $\begin{array}{l}\text { Strain TD } \\
(\%)\end{array}$ \\
\hline AEM/ CEM 1 & $\begin{array}{l}\text { knitted } \\
\text { fabric } 1\end{array}$ & 139 & 13.5 & 26.0 & 71 & 101 & 38 & 21 & 90 \\
\hline AEM/ CEM 2 & $\begin{array}{l}\text { knitted } \\
\text { fabric } 2\end{array}$ & 90 & 13.5 & 25.5 & 62 & 109 & 34 & 17 & 109 \\
\hline AEM/ CEM 3 & $\begin{array}{l}\text { knitted } \\
\text { fabric } 3\end{array}$ & 112 & 12.8 & 25.0 & 67 & 98 & 38 & 21 & 92 \\
\hline AEM/ CEM 4 & $\begin{array}{l}\text { woven } \\
\text { fabric }\end{array}$ & 100 & 32.0 & 35.0 & 67 & 220 & 238 & 28 & 28 \\
\hline
\end{tabular}

properties (permselectivity and electrochemical resistance) are usually changed during hot pressing $[1,2]$.

The optimum values of parameters (temperature $20-140^{\circ} \mathrm{C}$, pressure $10-13 \mathrm{MPa}$, exposure duration $10-600 \mathrm{~s}$ ) of hot pressing of heterogeneous IEMs are discussed by Zabolotskii et al. [1]. The optimum values of parameters of hot pressing of heterogeneous ion-exchange membranes with the aim of creating geometrical profiles on their surfaces are determined. It is shown that the major problem in the production of structured heterogeneous membranes is encapsulation of particles of the ion exchange resin in an inert polyethylene film, which leads to an increase in the surface resistance [1].

The same process for making heterogeneous IEMs with a geometric relief on the surface is presented in the Russian patent by Zabolotskii et al. [10]. The invention ensures the increase of the active surface of the IEMs, reduction of the value of their adhesion power and elimination of the thermo-destruction [10].

Güler et al. [14] prepared self-supporting membranes with flat, straight-ridge, wave and pillar structures by casting a polymer solution to eliminate the use of the spacers. Ion exchange membranes by surface patterning of a drying polymer solution in contact with a regular membrane spacer were produced by Balster et al. [12]. The same patterned ion-exchange membranes with integrated spacers were prepared and applied in ED by Liu et al. [5].

A variety of geometrical structures can be created on a surface of ion exchange membranes; straight-ridge, wave, pillar structures with a trapezoidal, conical and cylindrical shape [11]. Depending on the number of structures per unit, surface area and the dimensions of the structures on the membrane surface, pillar structures generally provide a more open area for water flow due to their high channel-to-structure ratio [15].

We can differentiate two types of IEMs. The first type is homogeneous IEM, which is composed of cross-linked polymers with ion exchange groups and the second type is heterogeneous IEM, which consists of polymer matrix (PE, PP, etc.), ion exchange resin and additives. Both types are often reinforced with fitting fabrics (PES, PP, PA). The concentration of ion-exchange particles in the matrix varies between 50 and $70 \mathrm{wt} \%[16,17]$.
Homogeneous membranes have excellent electrochemical properties but their mechanical strength is not so good. In contrast heterogeneous membranes have very good mechanical strength but their electrochemical properties are relatively poor [18].

This article focuses on the preparation of the heterogeneous ion exchange membrane with a special surface structure made with three types of knitted fabric. Structured ion exchange membranes were prepared together with the membrane with the flat surface to compare the influence of geometrical structures on the behaviour of ion exchange membrane properties.

Electrochemical, mechanical and physical properties were determined. Some transport parameters were measured in an electrodialysis stack with two concentrations of solution. Two electrodialysis stacks with different sizes of active area were used for comparison.

\section{Experimental \\ 2.1 Preparation of IEMs}

Structured IEMs were prepared from standard non-reinforcing heterogeneous ion exchange membranes (Ralex ${ }^{\circledR}$, Mega a.s. and MemBrain s.r.o.) using three types of knitted fabric (Zora, Silk \& Progress) by hot pressing (hydraulic press ZHOT, Presshydraulika, $135^{\circ} \mathrm{C}, 10 \mathrm{~min} / 2.5 \mathrm{MPa}$ and cooling to $65^{\circ} \mathrm{C}$ ) with lamination step on both sides with a reinforcing fabric. The membrane with a flat surface for comparison with structured IEMs was prepared in the same way using a woven fabric (Ulester, Silk \& Progress). The properties of knitted fabrics and descriptions of membranes (CEM cation exchange membrane, AEM anion exchange membrane) are summarized in Table 1. The screen of used fabric can be seen in Fig. 1. The knitted fabrics only differed from each other in the various thickness and number of fibres in warp and weft.

The influence of the different construction of the fabric (knitted and woven), special structure was made on the surface of the same IEMs. This is because the knitted fabric composed of a multifilament yarn and polymer matrix with ion exchange resin has a problem to fill its structure. Due to swelling, a special structure then forms on the surface of IEMs with knitted fabrics. 

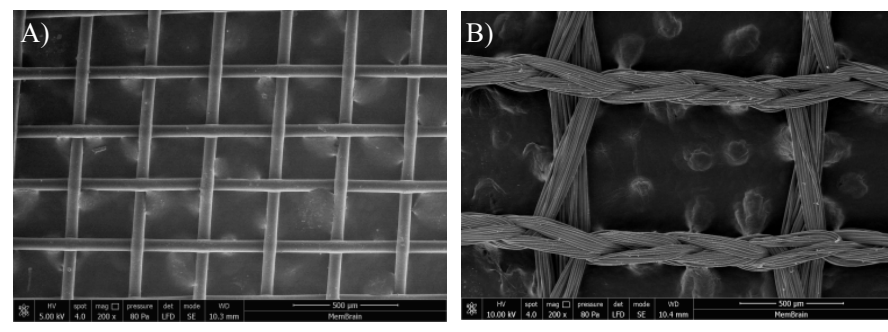

Fig. 1 Microscopic images of A) woven fabric and B) knitted fabric 1 taken by SEM

\section{2 lon exchange capacity (IEC)}

First, the IEMs were swollen in demineralized water. Then, they were conditioned in $1 \mathrm{~mol} \mathrm{dm}^{-3} \mathrm{NaOH}$ solution (p. a., $40 \mathrm{~g} \mathrm{~mol}^{-1}$, Penta) and converted into the corresponding form using $1 \mathrm{~mol} \mathrm{dm}^{-3} \mathrm{HCl}$ solution ( $35 \%$ p. a., $36.45 \mathrm{~g} \mathrm{~mol}^{-1}$, Penta) in the subsequent step. The next step was drying at the temperature of $105{ }^{\circ} \mathrm{C}$. The AEMs were immersed into $\mathrm{NaNO}_{3}$ solution ( $4 \% \mathrm{w} / \mathrm{w}$, p. a., $85.01 \mathrm{~g} \mathrm{~mol}^{-1}$, Lach-Ner), and the released amount of $\mathrm{Cl}^{-}$ions was determined by titration (Metrohm, 682 Titroprocessor, WTW pH-Electrode SenTix 61), Mohr's method being used. On the other hand, CEMs were immersed into $0.1 \mathrm{~mol} \mathrm{dm}^{-3} \mathrm{NaOH}$ and IEC was determined from equivalence point $[19,20]$. Error determination of IEC is $1 \%$.

\subsection{Relative water content}

The relative water content was determined in the following way. IEMs were dried in an oven (WTB Binder) at $75^{\circ} \mathrm{C}(5 \mathrm{~h})$ and $105{ }^{\circ} \mathrm{C}(1 \mathrm{~h})$ to a constant weight and weighed in the dry form $m_{\text {dry }}$. Subsequently, the IEMs were swollen in demineralized water at $25^{\circ} \mathrm{C}$ for $24 \mathrm{~h}$ and dabbed with filter paper to remove excess water. The weight of IEMs in the wet form was measured $m_{\text {wet }}$. Then the relative water content was determined by Eq. (1).

$$
r w c \%=\frac{m_{\text {wet }}-m_{\mathrm{dry}}}{m_{\mathrm{dry}}} \times 100
$$

Error determination of relative water content is given by the accuracy of the analytical balance, and is $0.5 \%$.

\subsection{Areal and specific resistance}

IEMs for measuring resistance (areal resistance $R_{\mathrm{A}}, \Omega \mathrm{cm}^{2}$ and specific resistance $R_{\mathrm{s}}, \Omega \mathrm{cm}$ ) were swollen in demineralized water at $25{ }^{\circ} \mathrm{C}$. The next operation was the same as in the IEC measurement (conditioning). The IEMs were equilibrated with $0.5 \mathrm{~mol} \mathrm{dm}^{-3} \mathrm{NaCl}$ (p. a., $58.44 \mathrm{~g} \mathrm{~mol}^{-1}$, Lach-Ner) for 24 h. Electrochemical resistance was measured in $0.5 \mathrm{~mol} \mathrm{dm}^{-3}$ $\mathrm{NaCl}$ solution at $25^{\circ} \mathrm{C}$ in a special experimental cell (specially manufactured for MemBrain s.r.o.) using a compensation method. The experimental cell consisted of two parts separated from each other. The appropriate solution was mixed in an experimental cell. Electrochemical resistance was measured between reference electrodes (silver - silver chloride, RAE $111-\mathrm{Ag} / \mathrm{AgCl}, \mathrm{Monokrystaly} \mathrm{s.r.o.)} \mathrm{and} \mathrm{then} \mathrm{constant} \mathrm{direct}$ current $(I=10 \mathrm{~mA})$ was applied between platinum electrodes (electrodes series PPE, Monokrystaly s.r.o.). Electrochemical resistance was determined from two measurements of potential difference. The first measurement of potential was performed without the IEM (only solution, $U_{\text {solution}}$ ) and the second with the IEM $\left(U_{\text {solution + IEM }}\right)$ between the two parts $[19,20]$. The active area $\left(S, \mathrm{~cm}^{2}\right)$ of the IEM was $0.785 \mathrm{~cm}^{2}$. The thickness $(t h, \mathrm{~cm})$ of the IEMs was determined using a micrometre. Specific and areal resistance was determined by Eq. (2) and Eq. (3).

$$
\begin{gathered}
R_{\mathrm{s}}=\frac{\left(U_{\text {solution }+\mathrm{EEM}}-U_{\text {solution }}\right)}{I} \frac{S}{t h} \\
R_{\mathrm{s}}=t h R_{\mathrm{A}}
\end{gathered}
$$

\subsection{Permselectivity}

Permselectivity $(P, \%)$ of IEMs was determined by Henderson's method in the same measuring cell as electrochemical resistance but with the following $\mathrm{KCl}$ solution (p. a., $74.56 \mathrm{~g} \mathrm{~mol}^{-1}$, Penta) pair $0.1-0.5 \mathrm{~mol} \mathrm{dm}^{-3}$ in separated parts and without applied direct current. Potential $\left(U_{\text {meas. }}\right)$ was measured between reference electrodes (calomel RCE $101-$ $\mathrm{Hg} / \mathrm{Hg}_{2} \mathrm{Cl}_{2}$, Monokrystaly s.r.o.). Permselectivity is determined by Eq. (4).

The IEMs were equilibrated with $0.5 \mathrm{~mol} \mathrm{dm}^{-3} \mathrm{KCl}$ for $24 \mathrm{~h}$ before the measurement $[21,24]$.

$$
P=\frac{U_{\text {meas. }}}{U_{\text {theor. }}} x 100
$$

where $U_{\text {theor }}$ is the potential from Nernst's law (Eq. (5)). $T$ is the temperature, $\mathrm{R}$ is the gas constant, $\mathrm{F}$ is the Faraday's constant and $a$ is the activities of anions or cations in the solution (1 or 2).

$$
U_{\text {theor. }}=-\frac{\mathrm{R} T}{2 \mathrm{~F}} \ln \frac{a_{\mathrm{K} 1} a_{\mathrm{A} 1}}{a_{\mathrm{K} 2} a_{\mathrm{A} 2}}
$$

\subsection{Mechanical properties}

The mechanical properties of the membranes were measured with samples of dimensions of $25 \mathrm{~mm} \times 150 \mathrm{~mm}$ (clamping length) according to the EN ISO 527-3 standard using an H5KT (Tinius Olsen) tensile testing machine with a speed of $5 \mathrm{~mm} \mathrm{~min}{ }^{-1}$. The direction stress was in the warp and weft direction (MD - machine direction/TD - transverse direction). Error determination of mechanical properties is $5 \%$.

\subsection{Morphology}

The morphology of the prepared membranes (membrane surface and cross-section) was investigated using a FEI Quanta 250 FEG scanning electron microscope (SEM). The conditions for measurements with the SEM were $5 \mathrm{kV}$ voltage, and a high vacuum ( $4.5 \times 10^{-3} \mathrm{~Pa}$ pressure) ETD (Everhart Thornley detector) for secondary electrons. An optical stereoscopic digital microscope DSTM 13 (Intracomicro) was used as a second microscope. 
Table 2 Measured properties of structured heterogeneous IEMs (MD - machine direction, TD - transverse direction)

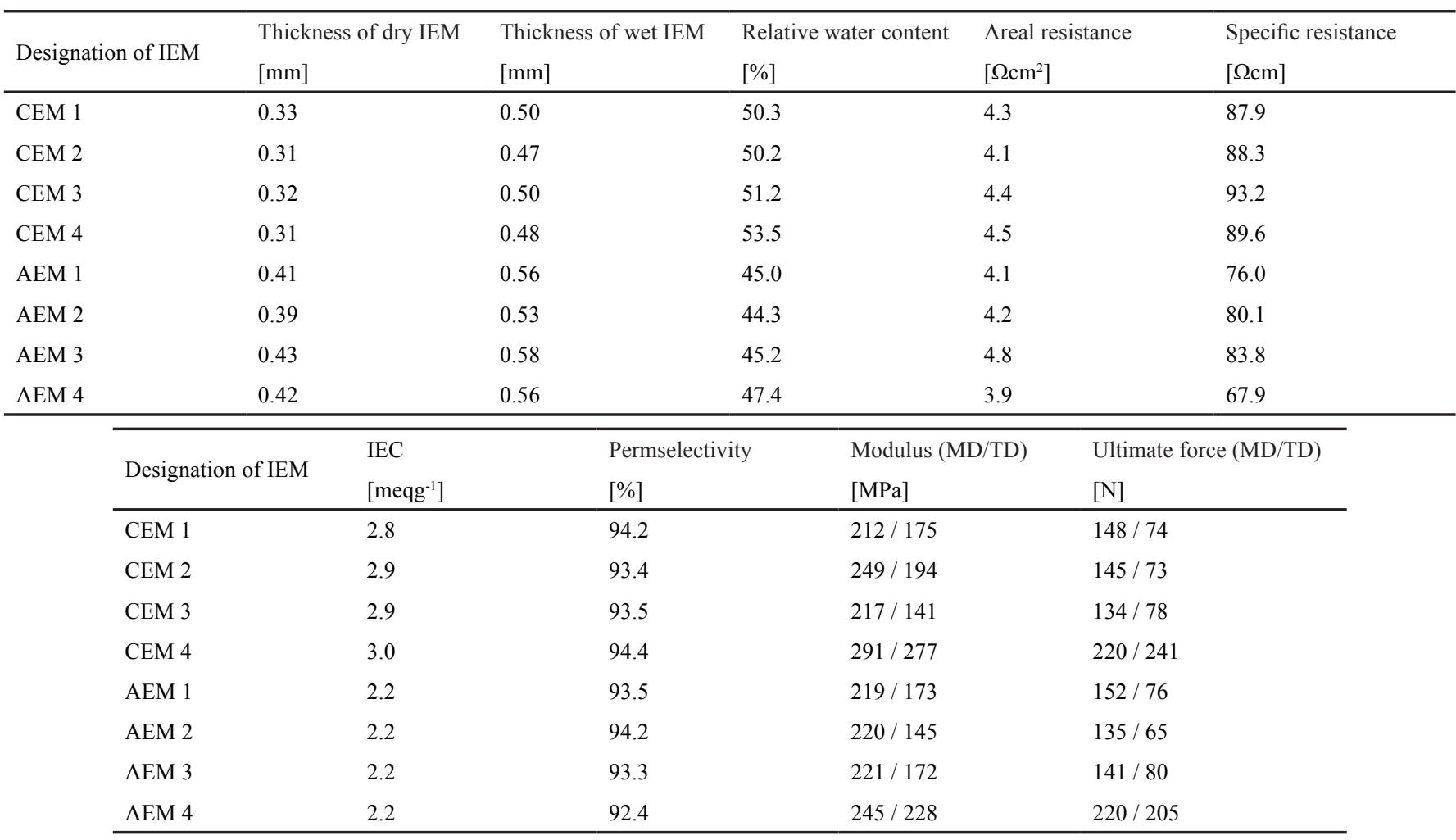

\subsection{Transport characterization by testing in an ED stack}

Experiments, which simulate the real conditions occurring during the process of ED, were performed using an electrodialyser (Supplier of ED unit is MemBrain s.r.o.). Two sizes of ED stacks were used with an active area of $0.064 \mathrm{~m}^{2}$ (named laboratory ED-Z) and $0.4 \mathrm{~m}^{2}$ (named pilot ED-Y). The active areas of ED stacks were calculated using the active area of one piece of IEM and a number of pairs of IEMs. A ten-pair stack of membranes with spacers was set into the unit. The initial concentrations of $\mathrm{Na}_{2} \mathrm{SO}_{4}$ (p. a., $142.04 \mathrm{~g} \mathrm{~mol}^{-1}$, Penta) were $20 \mathrm{~g} \mathrm{l}^{-1}$. The concentration of the second solution was $1 \mathrm{~g} \mathrm{l}^{-1}$. Solutions with the same concentration were used for diluate [22], concentrate and electrode stream (or electrode rinse solution). The batch system was tested with an initial volume of $1 \mathrm{~L}(4.7 \mathrm{~L})$ of diluate, $1 \mathrm{~L}(5 \mathrm{~L})$ of concentrate and $0.25 \mathrm{~L}(5$ L) of electrode stream for ED-Z (respectively ED-Y). Flows of solution were adjusted so that the linear velocity was $5.2 \mathrm{~cm} \mathrm{~s}^{-1}$ for both stacks. The voltage was constant at $10 \mathrm{~V}$ for all stacks. The temperature was stable at $25^{\circ} \mathrm{C}$.

The requirement for a successful experiment was final conductivity equal to $5 \%$ of the initial conductivity of solution. The measured parameters (WTW Multi 340i) were conductivity (WTWTetraCon 325) of diluate, concentrate and electrode stream, temperature, $\mathrm{pH}$ (WTW pH-Electrode SenTix 61), voltage and current of stacks (Fluke 289 True RMSmultimeter).

From the recorded data, common characteristics of electrodialysis process were evaluated. Current efficiency $\eta$ was calculated using Eq. (6).

$$
\eta=\frac{v_{C} z_{C} F \Delta n}{N Q} 100 \%
$$

where $Q[\mathrm{C}]$ is the electric charge, $v_{C}$ the stoichiometric coefficient of cations in compound, $z_{C}$ the valence of cations, $F$ [C $\left.\mathrm{mol}^{-1}\right]$ the Faraday constant, $\Delta n[\mathrm{~mol}]$ the amount of substance transported from diluate to concentrate (the amount of transported salts, the difference of salts at the beginning and at the end of the experiment), $N$ the number of membrane pairs in the electrodialysis stack (the sum of used CEMs and AEMs in the ED stack. We used the ten-pair stack).

Mass flux $J\left[\mathrm{~kg} \mathrm{~m}^{-2} \mathrm{~h}^{-1}\right]$ was calculated using Eq. (7).

$$
J=\frac{\mathrm{M} \Delta n}{N w L \Delta t}
$$

where $M\left[\mathrm{~kg} \mathrm{~mol}^{-1}\right]$ is the molecular mass of the compound, $w[\mathrm{~m}]$ the effective width of the membrane, $L[\mathrm{~m}]$ the effective length of the membrane and $\Delta t[\mathrm{~h}]$ the duration of the experiment [23].

\section{Results}

The electrochemical, mechanical and physical properties of the IEMs were measured. The measured data for the IEMs are presented in Table 2. Tensile curves for selected samples of AEMs are shown in Fig. 2. Tensile curves for CEMs showed the same trends as those for AEMs.

The difference in the thicknesses of the individual IEMs was only given by the used knitted fabric. AEMs and CEMs differed from each other by about 100 microns, because a different standard IEM was used for preparation. The relative 
water content of CEMs was greater than 50\% and for AEMs was around $45 \%$. This is due to the different swelling capacity of the ion exchange resins. In most cases, AEMs swell slightly less than CEMs. If the relative water content of IEMs was less than $35-40 \%$, IEMs would have low relative water content and high electrochemical resistance, causing an increase in the power consumed during electrodialysis tests.

Areal resistances for all types of CEMs and AEMs had the same values of around $4-5 \Omega \mathrm{cm}^{2}$. The specific resistance related to the thickness of the swollen membrane is more suitable for comparing all IEM types. There were already noticeable differences. The permselectivity of IEMs was higher than $92 \%$, which was positive for heterogeneous IEMs. IEMs 4 varied in their mechanical properties in the warp and weft compared to IEMs $1-3$. IEMs 4 had high mechanical strength and low elongation in both directions of stress. IEMs $1-3$ had high elongation and lower strength in the weft.

The CEM 4 with a flat surface and the structured CEM 1 are compared in Fig. 3. It can be seen form the profile that the CEM 4 was relatively flat. In some places it is only seen crossing the warp and weft threads of the used woven fabric.

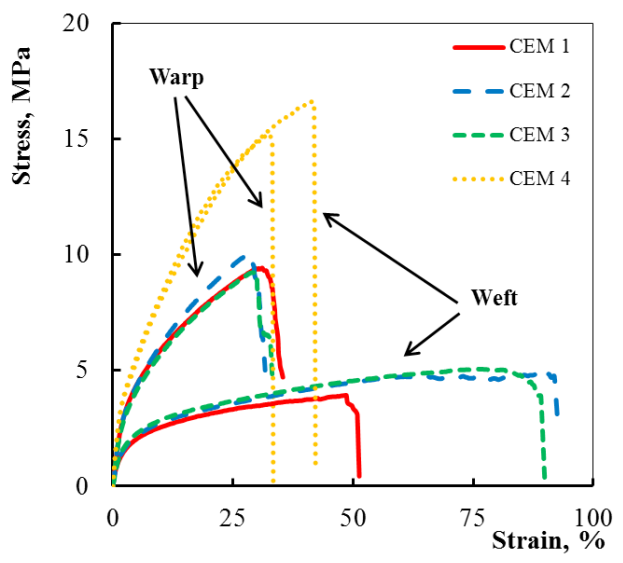

Fig. 2 Tensile curves of 4 types of CEMs in the warp and weft direction

In Fig. $\mathrm{C}$, the used knitted fabric in CEM 1 is already very visible after swelling. The special structure is more noticeable in the image (Fig. 3 D) of the CEM 1 profile.

The dimension of the pillars was only a few micrometres high. But even such small structures should play an important role in the transport properties of the electrodialysis stack. Their influence is discussed in the available literature $[1,5,10]$.

At the beginning of electrodialysis testing, spills and overflows were measured, and the solution was allowed to circulate in the electrodialysis unit in order to achieve sufficient swelling of the IEMs. At the same time, it is restricted to avoid excessive tightening, which is reflected in the reduction of the flow of solution. Subject to these conditions, spills and overflows were minimal and ranged in the millilitres during electrodialysis tests.
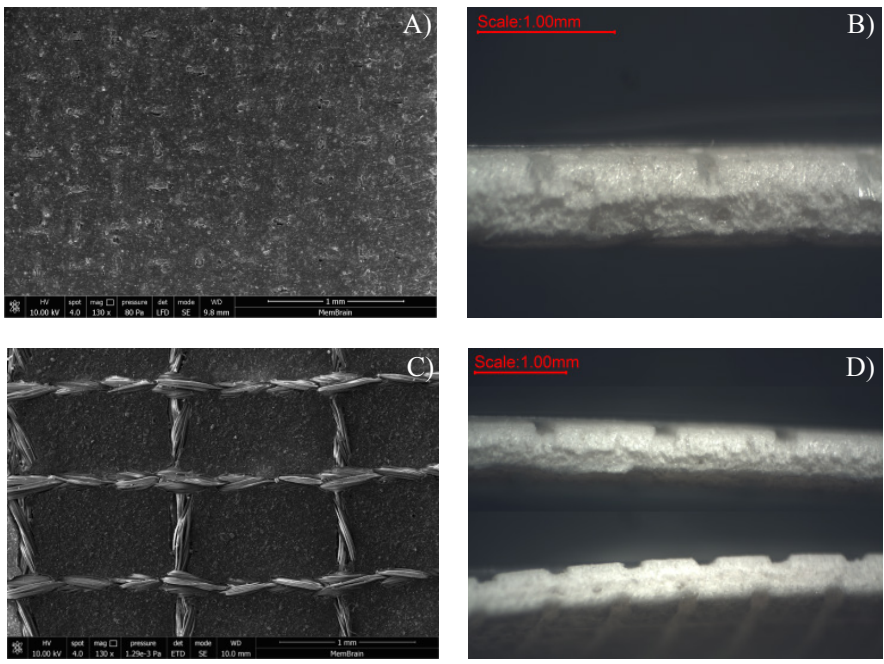

Fig. 3 Microscopic images of the selected IEM; A) surface of CEM 4; B) profile of CEM 4 after swelling, C) surface of CEM 1 and D) profile of CEM 1 after swelling in water taken by optical microscope and SEM, scale bars: $1 \mathrm{~mm}$

The first measurement of transport characteristics in the smaller ED stack is presented in Fig. 4, Fig. 5 and Table 3. All measured characteristics of the structured IEMs 2 are worse. The time for a $95 \%$ decrease of conductivity of the diluate is longer for structured IEMs in both cases. The efficiency is lower for the used structured IEMs 2 compared to the used flat IEMs 4.

The measured data of transport characteristics at $20 \mathrm{~g} \mathrm{l}^{-1}$ were almost identical. The conductivity of the diluate fell faster for IEM 2 but the time for a 95\% decrease of conductivity of the diluate was finally slower. This may be due to increased back-diffusion of the ions from the concentrate to the diluate. Diluate conductivity increases and thereby the time of desalination extends. The back-diffusion is a slower process than the ion transfer by electric potential. These IEMs may not be suitable for such a high concentration difference in the diluate and the concentrate. The increase of mass transfer for structured IEMs was not confirmed.

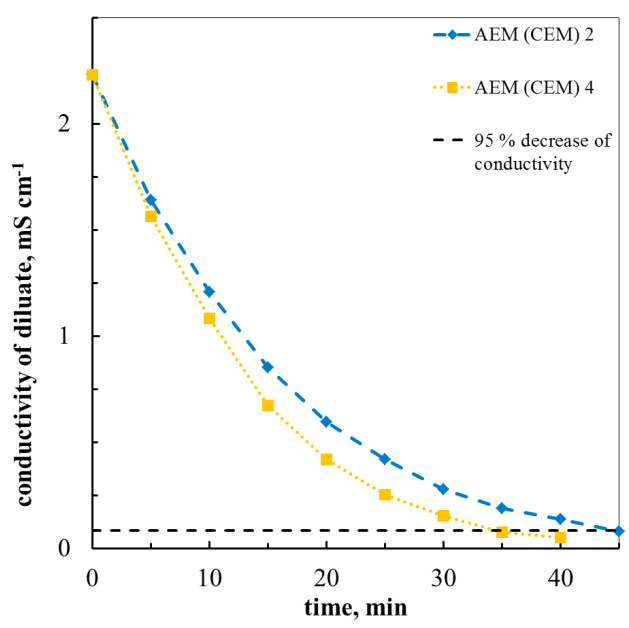

Fig. 4 Conductivity plotted against the time for IEMs in smaller stack (ED-Z) with initial concentration of solution $\mathrm{Na}_{2} \mathrm{SO}_{4} 1 \mathrm{~g} \mathrm{l}^{-1}$ 
Table 3 Data for transport test in laboratory stack ED-Z

\begin{tabular}{lllllll}
\hline \multirow{2}{*}{ ED-Z stack } & \multicolumn{3}{c}{ initial concentration $1 \mathrm{~g} \mathrm{l}^{-1}$} & \multicolumn{3}{c}{ initial concentration $20 \mathrm{~g} \mathrm{l}^{-1}$} \\
\cline { 2 - 6 } & $\begin{array}{l}\text { final time } \\
{[\mathrm{min}]}\end{array}$ & $\begin{array}{l}\text { efficiency } \\
{[\%]}\end{array}$ & $\begin{array}{l}\text { mass flux } \\
{\left[\mathrm{kg} \mathrm{m}^{-2} \mathrm{~h}^{-1}\right]}\end{array}$ & $\begin{array}{l}\text { final time } \\
{[\mathrm{min}]}\end{array}$ & $\begin{array}{l}\text { efficiency } \\
{[\%]}\end{array}$ & $\begin{array}{c}\text { mass flux } \\
{\left[\mathrm{kg} \mathrm{m}^{-2} \mathrm{~h}^{-1}\right]}\end{array}$ \\
\hline AEM (CEM) 2 & 42.6 & 73.9 & 0.035 & 67.0 & 84.5 & 0.322 \\
AEM (CEM) 4 & 32.8 & 90.2 & 0.070 & 66.7 & 87.9 & 0.346 \\
\hline
\end{tabular}

Table 4 Data for transport test in ED-Y pilot stack

\begin{tabular}{lllllll}
\hline & \multicolumn{3}{c}{ initial concentration $1 \mathrm{~g} \mathrm{l}^{-1}$} & \multicolumn{3}{c}{ initial concentration $20 \mathrm{~g} \mathrm{l}^{-1}$} \\
\cline { 2 - 7 } ED-Y stack & $\begin{array}{l}\text { final time } \\
{[\mathrm{min}]}\end{array}$ & $\begin{array}{l}\text { efficiency } \\
{[\%]}\end{array}$ & $\begin{array}{l}\text { mass flux } \\
{\left[\mathrm{kg} \mathrm{m}^{-2} \mathrm{~h}^{-1}\right]}\end{array}$ & $\begin{array}{l}\text { final time } \\
{[\mathrm{min}]}\end{array}$ & $\begin{array}{c}\text { efficiency } \\
{[\%]}\end{array}$ & $\begin{array}{c}\text { mass flux } \\
{\left[\mathrm{kg} \mathrm{m}^{-2} \mathrm{~h}^{-1}\right]}\end{array}$ \\
\hline AEM (CEM) 1 & 21.3 & 99.9 & 0.047 & 43.3 & 90.0 & 0.297 \\
AEM (CEM) 2 & 17.6 & 76.8 & 0.048 & 43.4 & 79.3 & 0.355 \\
AEM (CEM) 3 & 26.8 & 85.4 & 0.029 & 53.5 & 99.6 & 0.289 \\
AEM (CEM) 4 & 19.7 & 92.6 & 0.044 & 38.9 & 85.1 & 0.395 \\
\hline
\end{tabular}

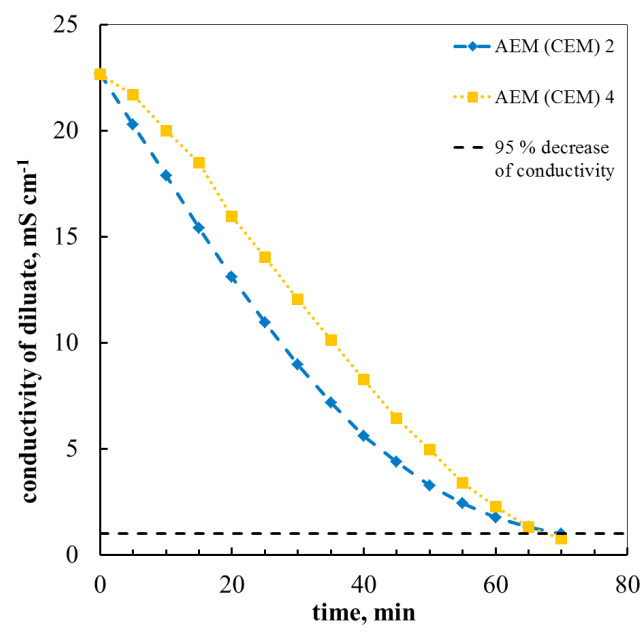

Fig. 5 Conductivity plotted against the time for IEMs in the smaller stack (ED-Z) with an initial solution concentration of $\mathrm{Na}_{2} \mathrm{SO}_{4} 20 \mathrm{~g} \mathrm{l}^{-1}$

These results were observed in the laboratory size, where greater weight is given to the ED-Y pilot stack with more than 6 times larger active area of the ED stack. The influence of structured membranes should exert more for larger EDY units. Higher volumes of solutions and a larger active area of the IEMs were used but the linear velocity of the solution was retained in both units. The measured data are summarized in Fig. 6, Fig. 7 and Table 4.

Structured IEMs $1-3$ have comparable or slightly worse transport characterization than flat IEMs. A 95\% decrease in the conductivity of the solution was achieved with flat IEMs 4 or IEMs 2 at 17 and 40 min for a low and high initial concentration of solution, respectively IEMs 2 show the lowest efficiency of all IEMs but have the highest values for mass flux.

Improving efficiency was not even confirmed in one type of structured IEMs as in [5]. The mass flux should have increased for structured IEMs [1], but this was not confirmed for one type of structured IEMs.

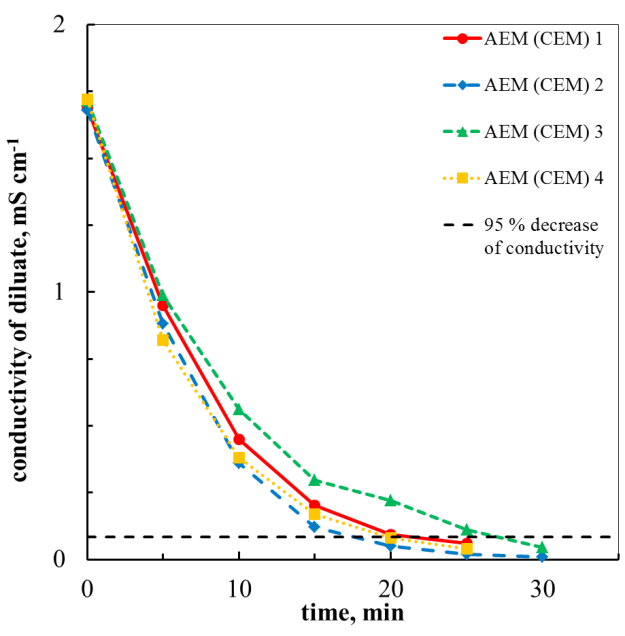

Fig. 6 Conductivity plotted against the time for IEMs in the bigger stack (ED-Y) with an initial solution concentration of $\mathrm{Na}_{2} \mathrm{SO}_{4} 1 \mathrm{~g} \mathrm{l}^{-1}$

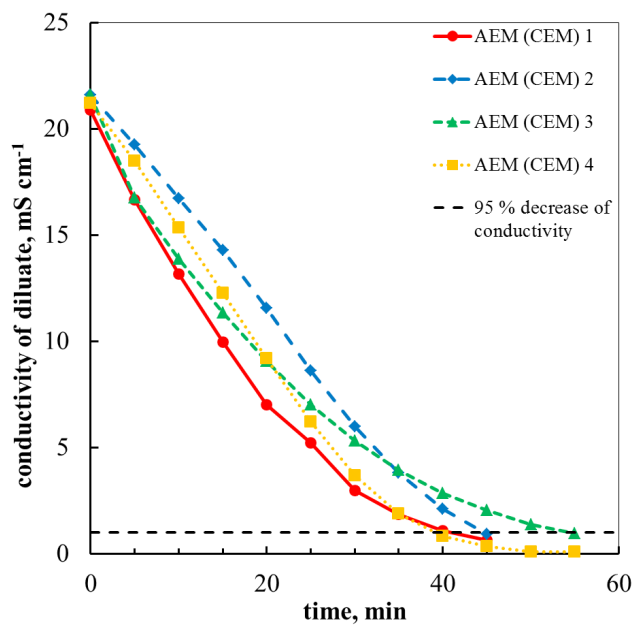

Fig. 7 Conductivity plotted against the time for IEMs in the bigger stack (ED-Y) with an initial solution concentration of $\mathrm{Na}_{2} \mathrm{SO}_{4} 20 \mathrm{~g} \mathrm{l}^{-1}$ 
Some influence on the process of desalinization was observed, but in almost all cases was negative. Maybe this was due to the fact that it was not possible to use the spacers in the ED stacks $[2,6,7]$. Clogging of solution inlets and an increase in the resistance of ED stacks occurred and it was not possible to set the desired flow of the solution through the unit. High values of spills and overflows (hundreds $100 \mathrm{ml}$ ) were measured.

It was not demonstrated that structured IEMs were not better than IEMs with a flat surface even though the comparable concentrations of input solutions $\left(10^{-1}\right.$ and $\left.10^{-3} \mathrm{~mol} \mathrm{dm}^{-3}\right)$ were used, as the authors [4].

\section{Conclusions}

Three types of structured IEMs were prepared. The electrochemical, physical and mechanical properties of these IEMs were measured. Transport characterizations in the laboratory and pilot units were analysed.

- The special structure on the surface of IEMs is visible. The dimension of the pillars is about dozens of micrometres.

- The structured IEMs have comparable values of resistance and permselectivity like the IEMs with a flat surface.

- Mechanical strength for structured IEMs is only different in the weft direction.

- An improvement in efficiency and mass flux for structured membranes was not confirmed.

- Structured IEMs were not better than IEMs with a flat surface under these conditions

As the next step, further arrangements of an electrodialysis unit will be tested and solution with mixed ions will be desalinated.

\section{Acknowledgement}

The work was carried out within the framework of project No. LO1418 „Progressive development of Membrane Innovation Centre" supported by the program NPU I Ministry of Education Youth and Sports of the Czech Republic, using the infrastructure of the Membrane Innovation Centre.

\section{References}

[1] Zabolotskii, V. I., Loza, S. A., Sharafan, M. V. "Physicochemical Properties of Profiled Heterogeneous Ion-Exchange Membranes." Russian Journal of Electrochemistry. 41, pp. 1053-1060. 2005. https://doi.org/10.1007/s11175-005-0180-2

[2] Vermaas, D. A., Saakes, M., Nijmeijer, K. "Power generation using profiled membranes in reverse electrodialysis." Journal of Membrane Science. 385-386, pp. 234-242. 2011. https://doi.org/10.1016/j.memsci.2011.09.043

[3] Strathmann, H. "Electrodialysis, a mature technology with a multitude of new applications." Desalination. 264(3), pp. 268-288. 2010. https://doi.org/10.1016/j.desal.2010.04.069
[4] Larchet, C., Zabolotsky, V. I., Pismenskaya, N., Nikonenko, V. V., Tskhay, A., Tastanov, K., Pourcelly, G. "Comparison of different ED stack conceptions when applied for drinking water production from brackish waters." Desalination. 222, pp. 489-496. 2008.

https://doi.org/10.1016/j.desal.2007.02.067

[5] Liu, J., Geise, G. M., Luo, X., Hou, H., Zhang, F., Feng, Y., Hickner, M. A., Logan, B. E. "Patterned ion exchange membranes for improved power production in microbial reverse-electrodialysis cells." Journal of Power Sources. 271, pp. 437-443. 2014.

https://doi.org/10.1016/j.jpowsour.2014.08.026

[6] Eigenberger, G., Grabovskiy, A., Strathmann, H. "Membrane assembly, electrodialysis device and method for continuous electrodialytic desalination." WO 2005009596 A1, Jan 03, 2005.

[7] Vermaas, D. A., Saakes, M., Nijmeijer, K. "Enhanced mixing in the diffusive boundary layer for energy generation in reverse electrodialysis." Journal of Membrane Science. 453, pp. 312-319. 2014.

https://doi.org/10.1016/j.memsci.2013.11.005

[8] "Electromembrane processes: state-of-the-art processes and recent developments developments." Institut für Chemische Verfahrenstechnik Stuttgart. 2009. URL: http://ocw.mit.edu

[9] Grabowski, A. "Electromembrane desalination processes for production of low conductivity water." Logos Verlag, Berlin. 2010.

[10] Zabolotskii, V. I., Loza, S. A., Sharafan, M. V. "Method of shaping of the heterogeneous ion-exchange membranes." RU 2284851 C1. 2006. URL: http://www.freepatent.ru

[11] Sheldeshov, N. V., Zabolotskii, V. I., Loza, S. A. "Electric Conductivity of Profiled Ion-Exchange Membranes." Petroleum Chemistry. 54, pp. 664-668. 2014.

https://doi.org/10.1134/S0965544114080143

[12] Balster, J., Stamatialis, D. F., Wessling, M. "Membrane with integrated spacer." Journal of Membrane Science. 360, pp. 185-189. 2010. https://doi.org/10.1016/j.memsci.2010.05.011

[13] Balster, J., Yildirim, M. H., Stamatialis, D. F., Ibanez, R., Lammertink, R. G. H., Jordan, V., Wessling, M. "Morphology and microtopology of cation-exchange polymers and the origin of the overlimiting current." Journal of Physical Chemistry B. 111, pp. 2152-2165. 2007. https://doi.org/10.1021/jp068474t

[14] Güler, E., Elizen, R., Saakes, M., Nijmeijer, K. "Micro-structured membranes for electricity generation by reverse electrodialysis." Journal of Membrane Science. 458, pp. 136-148. 2014.

https://doi.org/10.1016/j.memsci.2014.01.060

[15] Güler, E. "Anion exchange membrane design for reverse electrodialysis." Dissertation. University of Twente. 2014. URL: http://doc.utwente.nl

[16] Oren, Y., Freger, V., Linder, C. "Highly conductive ordered heterogeneous ion-exchange membranes." Journal of Membrane Science. 239, pp. 17-26. 2004.

https://doi.org/10.1016/j.memsci.2003.12.031

[17] Gnusin, N. P., Berezina, N. P., Kononenko, N. A., Dyomina, O. A. "Transport structural parameters to characterize ion exchange membranes." Journal of Membrane Science. 243, pp. 301-310. 2004. https://doi.org/10.1016/j.memsci.2004.06.033

[18] Vyas, P. A., Shah, B. G., Trivedi, G. S., Ray, P., Adhikary, S. K., Rangarajan, R. "Characterization of heterogeneous anion-exchange membrane." Journal of Membrane Science. 187, pp. 39-46. 2001. https://doi.org/10.1016/S0376-7388(00)00613-X

[19] Gohil, G. S., Shahi, V. K., Rangarajan, R. J. "Comparative studies on electrochemical characterization of homogeneous and heterogeneous type of ion-exchange membrane." Journal of Membrane Science. 240, pp. 211-219. 2004. https://doi.org/10.1016/j.memsci.2004.04.022 
[20] Agel, E., Bouet, J., Fauvarque, J. F. "Characterization and use of anionic membranes for alkaline fuel cells." Journal of Power Sources. 101, pp. 267-274. 2001.

https://doi.org/10.1016/S0378-7753(01)00759-5

[21] Cui, W., Kerres, J., Eigenberger, G. "Development and characterization of ion-exchange polymer blend membranes." Separation and Purification Technology. 14, pp. 145-154. 1998.

https://doi.org/10.1016/S1383-5866(98)00069-0

[22] Kůdela, V., Mikulášek, P., Palatý, Z. "English-Czech and Czech-English Explanatory Dictionary of Membranology." CZEMPo.s., Havlíčkův Brod. 2010.
[23] Dlask, O., Václavíková, N., Doležel, M. "Insertion of filtration membranes into electrodialysis stack and its impact on process performance." Periodica Polytechnica Chemical Engineering. 60(3), pp. 169-172. 2016. https://doi.org/10.3311/PPch.8539

[24] Sata, T. "Ion Exchange Membranes: Preparation, Characterization,Modification and Application." The Royal Society of Chemistry, Cambridge. 2004. 